\title{
Puzzling role of genetic risk factors in human longevity: "risk alleles" as pro-longevity variants
}

\author{
Svetlana Ukraintseva · Anatoliy Yashin · Konstantin Arbeev • \\ Alexander Kulminski • Igor Akushevich • Deqing Wu • \\ Gaurang Joshi $\cdot$ Kenneth C. Land $\cdot$ Eric Stallard
}

Received: 7 April 2015/Accepted: 19 August 2015/Published online: 26 August 2015

(C) Springer Science+Business Media Dordrecht 2015

\begin{abstract}
Complex diseases are major contributors to human mortality in old age. Paradoxically, many genetic variants that have been associated with increased risks of such diseases are found in genomes of long-lived people, and do not seem to compromise longevity. Here we argue that trade-off-like and conditional effects of genes can play central role in this phenomenon and in determining longevity. Such effects may occur as result of: (i) antagonistic influence of gene on the development of different health disorders; (ii) change in the effect of gene on vulnerability to death with age (especially, from "bad" to "good"); (iii) gene-gene interaction; and (iv) geneenvironment interaction, among other factors. A review of current knowledge provides many examples of genetic factors that may increase the risk of one disease but reduce chances of developing another
\end{abstract}

S. Ukraintseva $(\bowtie) \cdot$ A. Yashin · K. Arbeev ·

A. Kulminski · I. Akushevich · D. Wu .

K. C. Land · E. Stallard

Biodemography of Aging Research Unit, Center for Population Health and Aging, Social Science Research Institute, Duke University, Durham, NC 27708, USA

e-mail: svo@duke.edu

S. Ukraintseva · A. Yashin

Duke Cancer Institute, Duke University, Durham,

NC 27708, USA

G. Joshi

University at Buffalo School of Medicine and Biomedical

Sciences, Buffalo, NY, USA serious health condition, or improve survival from it. Factors that may increase risk of a major disease but attenuate manifestation of physical senescence are also discussed. Overall, available evidence suggests that the influence of a genetic variant on longevity may be negative, neutral or positive, depending on a delicate balance of the detrimental and beneficial effects of such variant on multiple health and aging related traits. This balance may change with age, internal and external environments, and depend on genetic surrounding. We conclude that trade-off-like and conditional genetic effects are very common and may result in situations when a disease "risk allele" can also be a pro-longevity variant, depending on context. We emphasize importance of considering such effects in both aging research and disease prevention.

Keywords Genetic risk factors - Trade-offs · Longevity $\cdot$ Aging $\cdot$ Physical senescence $\cdot$ Agespecific influence $\cdot$ Conditional effects $\cdot$ Epistasis . Gene-environment interaction · Complex disease

\section{Introduction}

Common complex diseases, such as cancer, cardiovascular diseases (CVD), diabetes, Alzheimer's disease (AD), and some other, are major contributors to mortality in old age. One might expect that genetic factors which increase risks of such diseases would negatively affect lifespan and be less common among 
long-lived people as compared to younger aged controls. A number of studies provided evidence in support of this expectation (Bonafe et al. 2002) (Benes et al. 2001; Cirulli et al. 2011; De Benedictis et al. 2001; Lescai et al. 2009; Nebel et al. 2011; Park et al. 2009, 2010; Ruiz et al. 2011). For example, it was found that the 192 QQ genotype of the PON1 (Paraoxonase 1) gene, which has been linked to a higher risk of cardiovascular events (Bhattacharyya et al. 2008), is under-represented among long-living Italians (Bonafe et al. 2002) (Lescai et al. 2009). Another study suggested that centenarians may carry fewer numbers of potentially deleterious alleles, such as rare variants of non-synonymous SNPs (Cirulli et al. 2011).

However, results of many other studies conducted over last two decades, including by authors of this paper, suggest that the presence of so called genetic "risk factors" for major diseases in individual genomes does not always compromise longevity, and that the share of such variants among centenarians is sometimes similar to that in a younger population (Galinsky et al. 1997; Mannucci et al. 1997; Schachter et al. 1994) (Bergman et al. 2007; Bladbjerg et al. 1999; Bonafe et al. 1999; Brattstrom et al. 1998; De Benedictis and Franceschi 1998; Holstege et al. 2011; Pepe et al. 1998; Yashin et al. 1999, 2001) (Beekman et al. 2010) (Freudenberg-Hua et al. 2014; Mooijaart et al. 2011; Sebastiani et al. 2011; Shi et al. 2012). For example, (Shi et al. 2012) found that of the ten most significant late-onset AD susceptibility genes that had been identified through several large genome wide association studies (GWAS), nine did not affect human lifespan, with the exception of APOE. Another recent study reported that many clinically relevant variants for cancer and other diseases, including those linked to autosomal dominant forms of pathology, are present in genomes of centenarians, suggesting that these variants are compatible with exceptional longevity (Freudenberg-Hua et al. 2014).

There may be different explanations for this phenomenon, including non-biological ones, such as flawed study design, differences in statistical approaches, publication bias, etc. There may also be real biological reasons. In this paper, we argue that trade-off-like and conditional effects of genes on phenotypes of health and aging may play a central role in the seemingly paradoxical behavior of the genetic "risk factors". We discuss several biological mechanisms of such effects, including: (i) antagonistic influences of genes on different health disorders; (ii) antagonistic effects of genes on vulnerability to death at different ages; (iii) gene-gene interaction (epistasis); and (iv) gene-environment interaction $(\mathrm{G} \times \mathrm{E})$, among other factors (Fig. 1).

\section{Trade-off-like influence of genes on different health traits}

Here we discuss the situation, in which a genetic variant may antagonistically influence two or more health phenotypes. For instance, it may increase risk of one disease, while reduce risk of another health condition, or improve survival from it. In case the beneficial effect overweighs the detrimental one, the net influence of such variant on survival may be overall beneficial and compatible with longevity.

A number of studies provided evidence of epidemiological trade-offs among major complex diseases as well as suggested their underlying biological mechanisms and potential impact on longevity (Ukraintseva et al. 2010; Yashin et al. 1999, 2001, 2009) (Akushevich et al. 2013). In particular, it was consistently demonstrated that individuals with $\mathrm{AD}$ may have lower risk of/mortality from cancer (Driver et al. 2012; Roe et al. 2010; Tabares-Seisdedos et al. 2011; Tabares-Seisdedos and Rubenstein 2013; Ukraintseva et al. 2010; Yashin et al. 2009) (Akushevich et al. 2013). Results of genetic association studies indicate that some genes may have opposing effects on the development of cancer and AD which could contribute to the epidemiological trade-offs.

For example, one of the most extensively studied genetic risk factors for $\mathrm{AD}$, the APOE e4 allele, was also found to be protective against cancer, as well as some other conditions, such as renal disease, liver damage and disability (Finch and Morgan 2007; Kulminski et al. 2011)(Hendrie et al. 2014; Kulminski et al. 2008). The trade-off-like influence of APOE on different health traits may partly explain why some studies could not find a significant association of the APOE polymorphism with longevity (Bader et al. 1998; Galinsky et al. 1997) (Kulminski et al. 2011). The effects of APOE can be modulated by age, sex, ethnicity and other factors, which will be discussed later. 


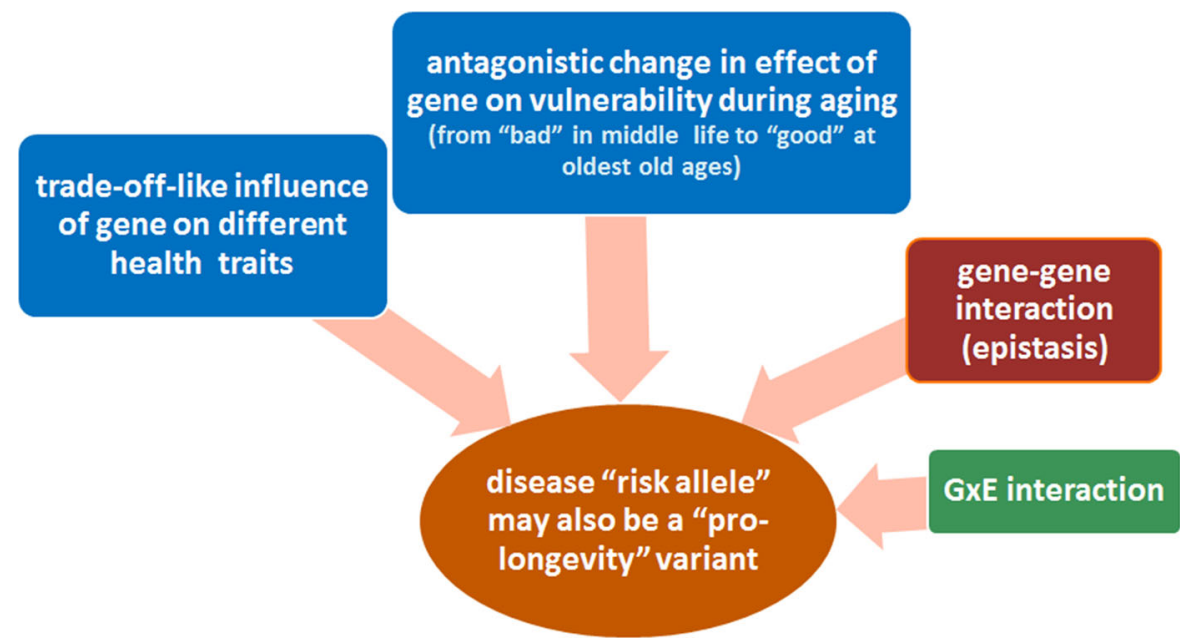

Fig. 1 Trade-off-like and conditional effects of genes on health and aging related traits might explain why genetic "risk factors" for major diseases do not always compromise longevity

Another broadly studied functional polymorphism, C677T (Ala ${ }^{222}$ Val) of the MTHFR (Methylenetetrahydrofolate reductase) gene, was also shown to antagonistically influence risks of $\mathrm{AD}$ and cancer. The 677T allele corresponds to an enzyme with reduced activity, and homozygous 677TT individuals have higher blood homocysteine levels similar to that observed in low dietary folate intake. The $677 \mathrm{~T}$ allele or TT genotype showed an inverse association with risks of colorectal cancer (protective effect) and $\mathrm{AD}$ (promoting effect) in a number of studies, including meta-analyses (Hua et al. 2011) (Huang et al. 2007) (Peng et al. 2015) (Hubner and Houlston 2007). The antagonistic role of 677TT was also suggested for different types and localizations of colorectal tumors. E.g., the TT genotype was associated with increased risks of proximal colon cancers and decreased risks of distal cancers (Iacopetta et al. 2009; Levine et al. 2010), with the overall effect being protective. As for longevity, the 677TT genotype showed slightly beneficial albeit non-significant effect on all-cause mortality in two large population-based studies (Husemoen et al. 2014; Yang et al. 2012). These results indicate that the risk-promoting and protective effects of the 677TT may offset each other, or the beneficial effect may even prevail in certain environments, which could potentially explain why this "risk genotype" for AD is often found in similar frequencies in the elderly and young people or enriched among the long-lived individuals in some study populations (Galinsky et al. 1997) (Chen et al. 2014b).

It is important to note that $\mathrm{G} \times \mathrm{E}$ may significantly modify the relationship between genetic polymorphism and health outcomes. For example, the protective effect of the MTHFR 677TT genotype on colorectal tumors can be strengthened in individuals with high dietary folate and low alcohol consumption, while low intakes of folate, methionine, vitamins B12 and B6, and high alcohol consumption (which depletes 5-methyltetrahydrofolate) may actually increase the risk of colon cancer in those with 677TT genotype (Chen et al. 1996; Iacopetta et al. 2009; Ma et al. 1997; Slattery et al. 1999; Ulrich et al. 1999). This indicates the potential of lifestyle interventions to reduce the disease risk attributed to genetic background. The $\mathrm{G} \times \mathrm{E}$ impact on longevity will be further discussed in a separate section below.

Many other genes currently known as disease "risk factors" were found to be protective against some serious health problems. For example, ACE (angiotensin I converting enzyme) causes blood vessels to narrow sending the blood pressure up, and the I/D polymorphism of the ACE is thought to influence this blood pressure regulation. The $\mathrm{D}$ allele corresponding to a higher level of serum ACE was linked to hypertension and more consistently to myocardial infarction (MI) (Rigat et al. 1990) (Cambien et al. 1992) (Higaki et al. 2000) (Chen et al. 2013). At the same time, a diminished risk of 
$\mathrm{AD}$ in $\mathrm{DD}$ genotype carriers was reported in several studies (Wang et al. 2006) (Alvarez et al. 1999) (Lehmann et al. 2005). Overall, available evidence indicates that the ACE I/D polymorphism may influence multiple health traits, sometimes in opposite directions, also depending on age and interactions with other genes, such as APOE (Wang et al. 2006). In case the deleterious and beneficial effects of ACE variants offset each other, or the beneficial effect prevails, the frequencies of ACE D allele (genetic risk factor for MI) may be similar or even higher in centenarians compared to younger controls, which is often observed in real data (Garatachea et al. 2013; Zajc Petranovic et al. 2012; Faure-Delanef et al. 1998).

Another established risk factor for CVD, lipoprotein (a) $[\mathrm{Lp}(\mathrm{a})]$, also shows a trade-off-like influence on major human diseases. Its elevated plasma levels are considered to be an independent risk factor for premature CHD, stroke and peripheral artery disease (Dahlen 1994; Enkhmaa et al. 2011; Erqou et al. 2009). Several LPA [lipoprotein, Lp(a)] genotypes, which result in elevated $\mathrm{Lp}(\mathrm{a})$ levels, were shown to increase the risk of CVD (Clarke et al. 2009). However, some of these genotypes were also found to be protective against cancer and other non-CVD disorders (Hsieh Wu 2011; Sawabe et al. 2012). This indicates that the impact of the "risk genotypes" for CVD on all-cause mortality and longevity may not necessarily be detrimental. This possibility is supported by research on associations of $\mathrm{Lp}$ (a) blood levels with longevity and various health disorders. An earlier study reported that mean $\mathrm{Lp}$ (a) levels are about the same in centenarians and younger controls; moreover, a quarter of healthy centenarians had the $\mathrm{Lp}$ (a) levels that might put them at risk for atherosclerosis (Baggio et al. 1998). The authors concluded that either Lp(a) level is not a risk factor for CVD in the very old, or it is offset by unknown protective factors. In a more recent longitudinal study of the Italian elderly (65-84 years of age), no significant association of $\mathrm{Lp}$ (a) serum levels with all-cause mortality was found (Solfrizzi et al. 2009). A meta-analysis of 36 prospective studies, with 126,634 participants in total, revealed that the high $L p(a)$ concentrations could indeed be considered a risk factor for CVD but not for non-vascular deaths including cancer deaths (Erqou et al. 2009). The trade-off-like influence of the Lp(a) on CVD and non-CVD related disorders might in part explain the lack of association of the Lp(a) levels with all-cause mortality.

Some studies also suggested that genetic variants that increase risks of autoimmune disorders may not necessarily adversely affect survival, or may even improve it, in case these variants also protect against some other serious health conditions (such as cancer or tuberculosis). For example, $\mathrm{G}$ allele of the $+49 \mathrm{~A} / \mathrm{G}$ polymorphism in the CTLA-4 (cytotoxic T lymphocyte antigen-4) gene playing a role in immunosuppression corresponds to a lower CTLA-4 expression and a higher $\mathrm{T}$ cell activation in response to stimuli. The $\mathrm{G}$ allele has been associated with increased risks of autoimmune conditions and decreased risk of overall cancer in a number of studies (Wang et al. 2015; Brozzetti et al. 2010; Ghaderi 2011; Hu et al. 2010). A trade-off-like association was also found for the tumor necrosis factor- $\alpha$ gene polymorphism with autoimmune disorders (such as lupus and rheumatoid arthritis) and tuberculosis (Correa et al. 2005). The higher risk of the autoimmune disorders could be a natural side effect of the enhanced immune resistance to potentially fatal conditions (tuberculosis and cancer).

Our group recently reported prominent trade-offlike effects of single nucleotide polymorphisms (SNPs) in the NRDE2 and ECHS1 genes on risks of cancer and CVD in Framingham Heart Study participants (Yashin et al. 2015). Male carriers of genotypes associated with better overall survival after age 80 had a lower risk of CVD but a higher risk of cancer at the same ages. The protective effect on CVD apparently outweighed the cancer promoting effect, so that the overall impact of these genotypes on survival after age 80 was beneficial. This study demonstrates that a prolongevity genotype can also be a risk factor for some major disease (here cancer). This implies that strategies of increasing human longevity through increasing healthy lifespan should be personalized and consider potential trade-offs.

Studies of non-genetic risk factors for major disorders support the idea that the antagonistic influence of the same factor on different health traits can be a common occurrence and contribute to longevity. For example, a high blood cholesterol and total/HDL cholesterol ratio are considered established risk factors for CHD mortality in middle to old age (e.g., Lewington et al. 2008). In a study of about 150,000 men and women aged 20-95 years, the high blood 
cholesterol levels ( $>248 \mathrm{mg} / \mathrm{dl}$ ) did predict death from CHD (Ulmer et al. 2004). This study, however, also found that low $(<187 \mathrm{mg} / \mathrm{dl})$ rather than high cholesterol was significantly associated with all-cause mortality after the age 50. In research focusing on the oldest-old $(85+)$ individuals, the lower total cholesterol $(<5.5 \mathrm{mmol} / \mathrm{l})$, as well as its larger annual decline, were associated with increased all-cause mortality, while the higher total cholesterol ( $\geq 6.5 \mathrm{mmol} / \mathrm{l}$ ) was associated with longevity, owing to a lower mortality from cancer, respiratory diseases and infections (Petersen et al. 2010; van Vliet et al. 2010; Weverling-Rijnsburger et al. 1997). These results indicate that the lower cholesterol levels, being indeed protective against CHD, may not be so beneficial in relation to other common disorders and total survival, especially in the very old.

Also worth mentioning is an evidence of trade-offs between risk and survival for the same disease. For example, women subjected to hormone replacement therapy had an almost two-fold reduction in the risk of colon cancer, while similarly increased risk of dying from this same cancer in case they got it (Hartz et al. 2012; Taylor and Manson 2011). Such results indicate that it is essential to evaluate the influence of candidate genetic risk factors not only on the risk of a targeted disorder, but also on survival from it, since some risk factors for disease incidence may also influence casefatality rates.

A general biological mechanism of genetic tradeoffs is likely related to differential roles the same biological process may play in the development of various health problems. For instance, suppressed apoptosis is one of the established hallmarks of cancer (Hanahan and Weinberg 2011). It may help transformed cells to escape programmed death and thus facilitate cancer development, while increased apoptotic activity may be cancer protective. On the other hand, the increased apoptosis is a typical feature of $\mathrm{AD}$, which contributes to excessive loss of brain cells in this disorder (Lee et al. 2012). If so, then genetic variants that manifest themselves in a chronically upregulated apoptosis in tissue may potentially be both cancer protective and AD promoting (discussed in Ukraintseva et al. 2010). Better understanding of underlying biological mechanisms of the genetic trade-offs, as well as specific conditions needed for their manifestation, is essential for both getting insights into the relationships between age-associated health decline and longevity, and for the development of efficient personalized prevention and treatments.

\section{Antagonistic change in effect of gene on vulnerability to death with age: from "bad" in middle life to "good" at oldest old ages}

Genes may change their impact on vulnerability to death during one's life. Here we will focus on the situation when a genetic variant can be associated with a higher vulnerability to death in middle life but may then become neutral or relatively beneficial at advanced ages (De Benedictis et al. 1998; De Benedictis and Franceschi 2006; Ukraintseva 2005; Yashin et al. 1999, 2001). The manifestation of such a variant as a risk or pro-longevity factor will thus depend on age. For a variant that changes its effect from risk promoting to protective towards extreme ages, the age-pattern of empirical allele frequency will not just increase or decline with age but rather demonstrate a non-monotonic behavior (Fig. 2). For example, in (Yashin et al. 1999) empirical frequencies of several mtDNA haplogroups followed a U-shape pattern: The frequency decreased over middle age, and then increased in the oldest-old age group, resulting in a relatively high frequency of the initially "harmful" variants among the long-lived individuals. The demographic model for such behavior of the allele frequencies corresponds to the intersection of mortality rates for populations of carriers and non-carriers of the particular allele, meaning that the initially deleterious effect of such allele on total survival can be transformed into a relatively beneficial one later in life (Fig. 2). A recent study provided an example of a SNP in the NRDE2 gene manifesting a survival trade-off: carriers of the homozygous major allele had negative effect on survival at ages before 80 , while positive effect afterwards, as compared with the minor allele carriers (Yashin et al. 2015).

One should note that this type of antagonistic change in effect of genotype on vulnerability with age (i.e., from "bad" to "good") is different from the case of the antagonistic pleiotropy typically discussed in connection with the evolutionary hypothesis of aging (e.g., Kirkwood and Rose 1991). The latter addresses the situation, in which a genotype may enhance fitness early in life or during the reproductive period at the cost of increasing risks of major diseases at the post- 
(a)

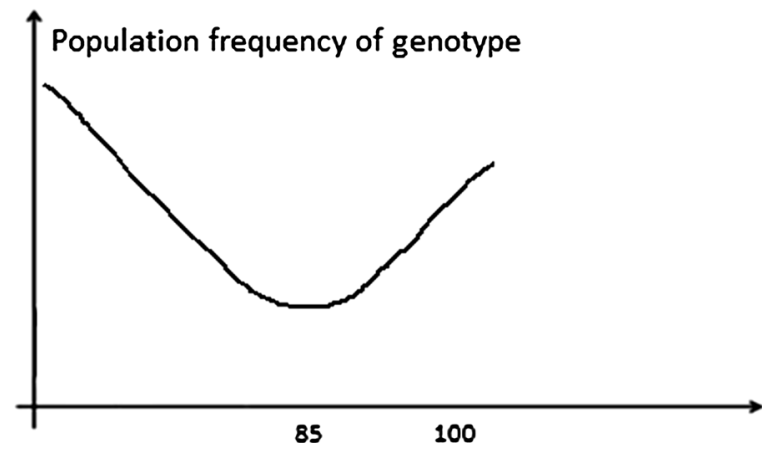

Fig. 2 Simplified illustration of potential consequences of the antagonistic change in effect of genotype on vulnerability to death with age: from increasing the relative vulnerability in middle life to decreasing it at oldest old ages (85+) (not actual data; for empirical examples see references in the text). a Population frequency of some "risk" genotypes may change non-monotonically (U-shape-like) with age: first decreasing

reproductive period. Here we focus on a different situation, in which a gene may change its effect on vulnerability to death from relatively "bad" in middle life to a relatively "good" at oldest old ages $(85+)$, so that this change mostly takes place in the postreproductive period.

How may a risk factor earlier in life become neutral or beneficial at extreme ages? Several biological mechanisms could contribute to such effect. Yashin and colleagues proposed that genes that promote a higher vulnerability to death in middle life may become less harmful or even beneficial at advanced ages due to aging changes in the internal environment (Ukraintseva 2005; Yashin et al. 1999, 2001). Indeed, aging and ontogeny related transitions in the body (e.g., from growth period to reproductive period to menopause to physical frailty) are accompanied by substantial changes in metabolism, body composition and hormonal profile, which can alter the internal milieu in which genes work. In such a changing environment, genes will not necessarily have the uniform effect on the same phenotype at all ages, and a risk factor for some disease in a middle-aged body may not always be the risk factor in an older body (Robinson et al. 2013; Ukraintseva and Yashin 2001; Yashin et al. 2001). A rise and then a decline of estrogen levels in female body with age, towards menopause, could be an example of a change in internal environment with age, due to ontogeny. The (b)

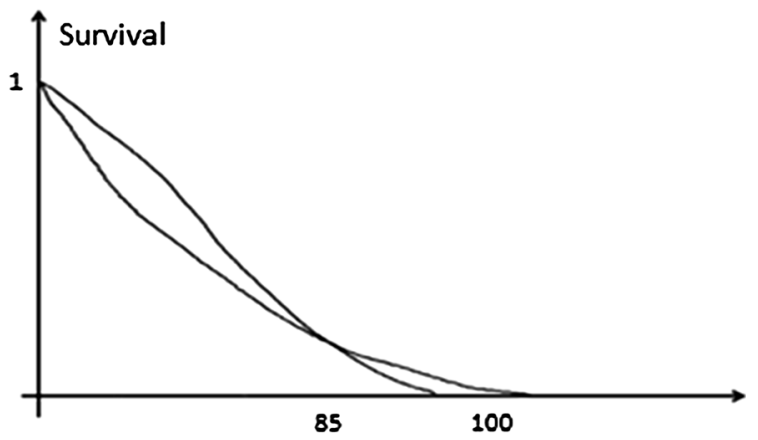

towards middle-old ages, and then increasing towards extreme ages (e.g., De Benedictis et al. 1998; Yashin et al. 1999; Bergman et al. 2007). b Intersection of survival functions for carriers of different genotypes may occur, so that genotype with initially negative effect on survival may have positive effect later in life, at oldest old ages (e.g., Yashin et al. 2001, 2015)

higher estrogen levels at the reproductive period may increase risks of certain cancers, e.g., of female endometrial cancer; however, after menopause there are no longer high estrogen levels in the female body, so this risk factor is no longer present, and the risk of endometrial cancer declines with advancing age accordingly (Ukraintseva et al. 2008; Ukraintseva and Yashin 2003a). Similarly, a genetic risk factor for cancer that acts through the elevation of estrogen levels may cease its cancer promoting effect towards the oldest-old age. Summarizing, one could say that the age-specific effects of genes could be a product of a changing internal $\mathrm{G} \times \mathrm{E}$ with age, and a reason that the risk factor in middle-aged body may not always be the risk factor in an older body.

Another potential mechanism may involve antagonistic influence of a gene on disease and senescence related phenotypes (e.g., Ukraintseva and Yashin 2003b). To better understand how this property may result in changing the impact of a gene on vulnerability to death with age, especially from deleterious to beneficial, consider a hypothetical example. Suppose, there is a gene variant that chronically upregulates production of a growth factor that promotes proliferation and suppresses apoptosis, and through this it may increase the body's susceptibility to cancer. However, due to the same growth promoting and anti-apoptotic properties, this variant may also postpone or attenuate some phenotypes of physical senescence, such as 
sarcopenia, muscle atrophy, physical frailty, reduced regenerative ability, slower response to infection and slower healing. Importantly, these (opposing) effects of gene variant on cancer and physical senescence may have a major impact on all-cause mortality predominantly at different ages. Indeed, a majority of cancers reach a peak incidence rate at ages before 80 ; after that cancer risk typically levels off or declines (Akushevich et al. 2012; Ukraintseva et al. 2008; Ukraintseva and Yashin 2003a). As result, cancer is major contributor to mortality at ages before 80 , but at the oldest old ages (85+) its relative impact on all-cause mortality diminishes. By contrast, the risks of many senescence-related conditions that may lead to death continue to increase towards the oldest old age, so that their relative contribution to the mortality risk becomes more pronounced than that of cancer at extreme ages. Examples of relevant conditions include poorly healed hip fractures and wounds due to slow regeneration, heart failure due to muscle atrophy, renal failure due to slow metabolism, complications of COPD, flu and pneumonia due to slower immune response, and other. Since mortalities from cancer and from senescence related causes have their peaks at different ages, a genetic variant that favors cancer but attenuates physical senescence may contribute to a higher total mortality risk in middle-old life (when cancer is major contributor to mortality), while to longevity afterwards, when senescence-related causes become leading contributors to the mortality risk (Akushevich et al. 2012; Lloyd-Jones et al. 2002; Neuman et al. 2014; Ruiz et al. 2014; Ukraintseva et al. 2008, 2010; Ukraintseva and Yashin 2003a; Yashin et al. 2001).

Additional examples show that the antagonistic effects of genetic factors on disease and senescence related phenotypes, or on the same phenotype at different ages, could be a common occurrence. An earlier study conducted on the Italian population found a non-monotonic age-trajectory of the frequency of the SS genotype of $3^{\prime}$-APOB-VNTR polymorphism (De Benedictis et al. 1998). That is, the SS frequency in the genotype pool increased from the young group to the middle-aged group and then it declined reaching its minimum value in centenarians. Next, Garasto et al. (2004) studied a correlation between various 3'APOBVNTR genotypes and blood lipid levels and concluded that the convex trajectory of the SS frequency could be explained by the fact that the $\mathrm{S}$ alleles are linked to a lower blood level of LDL-cholesterol, so that the SS genotype may be advantageous in adults by protecting them from CVD. It may, however, be disadvantageous in the very elderly, when the cholesterol level naturally declines, and its excessive lowering, below a critical threshold, could adversely affect tissue regenerative ability and increase mortality associated with a slower regenerative response due to aging (De Benedictis et al. 1998; De Benedictis and Franceschi 2006; Garasto et al. 2004).

A meta-analysis of published studies found that carriers of the Pro/Pro genotype of TP53, corresponding to a reduced apoptosis in cells, have an increased cancer risk compared to Arg/Arg genotype carriers (van Heemst et al. 2005). The same authors conducted a prospective study of individuals aged $85+$ and found that carriers of the Pro/Pro genotype had a significantly increased proportion of cancer deaths. Surprisingly, they also had a significantly increased overall survival (by $41 \%$ ), together with decreased proportion of deaths from other causes such as chronic obstructive pulmonary disease (COPD), renal failure, dementia, fractures and senility, which typically accompany physical senescence (van Heemst et al. 2005). That is, the Pro/Pro genotype showed a tradeoff-like influence on cancer and senescence related phenotypes. These results indicate that cancer treatment that enhances apoptosis among carriers of the Pro/Pro genotype may promote their survival from cancer but increase risk of death from other aging related disorders.

Elevated levels of plasminogen activator inhibitor1 (PAI-1) have been linked to CVD and metabolic syndrome (Coffey et al. 2011; Leander et al. 2003). In accord, the 4G4G genotype of the PAI-1 gene, which is associated with a high plasma level of PAI-1, was linked to increased risk of atherothrombosis and MI, as well as to oral cancer, in several studies (Vairaktaris et al. 2006) (Gong et al. 2012) (Vylliotis et al. 2013) (Nikolopoulos et al. 2014). However, the frequency of the PAI-1 4G4G genotype was found to be similar in older $(85+)$ and younger $(<65)$ individuals (Heijmans et al. 1999) (Bladbjerg et al. 1999), or even higher in centenarians compared to younger controls (Mannucci et al. 1997) (Mari et al. 2008). Importantly, in Heijmans et al. (1999), the risk of fatal heart disease was significantly increased in elderly men (85+) carrying the $4 \mathrm{G} / 4 \mathrm{G}$ genotype, while the risk of allcause mortality was not increased at all $(R R=0.9$, 
$95 \%$ CI 0.7-1.1). This indicates that the 4G4G genotype is still a disease risk factor in the very old, but this is compatible with longevity. One potential explanation could be that the $4 \mathrm{G} / 4 \mathrm{G}$ genotype may protect older people against another fatal disease or senescence related condition with high impact on the oldest old mortality, so that the deleterious and beneficial effects can offset each other. Results of several studies suggest that this might be the case: increased PAI-1 levels were shown to reduce chances of fatal bleeding and improve wound healing (Iribarren et al. 2008; Iwaki et al. 2011). The latter can be essential for survival at older ages, when the body's resistance to damage deteriorates and recovery slows down. Since medical treatment of the $4 \mathrm{G} / 4 \mathrm{G}$ carriers from fatal heart disease may change this delicate balance, one should consider interventions that do not compromise total survival.

Several groups reported changes in the effect of a gene (from deleterious to neutral or beneficial) on the same health trait with increasing age of study participants. For example, Kulminski et al. reported agedependency of the effect of APOE e4 allele on onset of CVD in the Framingham Study sample (Kulminski et al. 2013). The authors showed that the e 4 allele was a risk factor for CVD at ages before 76 years in women, but a rather protective factor at older ages (76+). In a study of the IRF4 (interferon regulatory factor 4) gene polymorphism (Duffy et al. 2010) found that the T allele of the SNP rs12203592 was associated with high melanocytic nevus counts in young adults, but with low counts in older adults. Since a high melanocytic nevus count is considered to be a predictor of melanoma risk, these results suggest that younger people may have higher risk of melanoma than older ones owing to the same allele. Another study showed that a mutation in a gene for haemochromatosis was linked to various diseases in middle age; however, no association with morbidity, all-cause and cause-specific mortality has been found for the same mutation in the oldest-old age group (85+) (van Aken et al. 2002).

Results of many studies also suggest a high prevalence of trade-off-like and age-specific effects of non-genetic factors on various health traits. Below are few examples, which provide additional insights into mechanisms of respective genetic effects. A downregulation of IGF-1 has been associated with both cancer protection and cardiovascular risks
(Bartke 2012; Conti et al. 2011; Sonntag et al. 2012; Ungvari and Csiszar 2012). The higher levels of IGF-1 were linked to both cancer and an almost twofold reduction in the risk of heart failure in the elderly (Renehan et al. 2004; Vasan et al. 2003), as well as to attenuation of other phenotypes associated with physical senescence, such as frailty, sarcopenia, muscle atrophy, and to better muscle regeneration (Vasan et al. 2003) (Conti et al. 2011; Musaro 2012; Renehan et al. 2004; Vinciguerra et al. 2010; Werner and Bruchim 2012).

A meta-analysis of 36 prospective studies exploring the effect of Lp(a) concentrations on CVD and nonCVD risks showed that the association of high Lp(a) levels with CVD steadily declined with age and remained significant only at ages below 70, but not afterwards (Erqou et al. 2009). This indicates that $\mathrm{Lp}$ (a) genetic variants that had been linked to a higher Lp(a) levels (Clarke et al. 2009) may also diminish their effect on CVD in advanced age.

High blood pressure is viewed as a risk factor for renal disease (Hsu et al. 2005); however, it appears to cease being such a risk factor in the oldest-old (van Bemmel et al. 2006). Also, an elevated systolic blood pressure (SBP) in older men (mean age 68 years) was associated with the lowest risk of death from all causes combined. The same values of SBP in the same sample were associated with a 15 times increased risk of end stage renal disease (Agarwal 2009). These results indicate that the same risk factor (blood pressure), and possibly genes that regulate its manifestation (such as ACE and other), may be involved in multiple types of trade-offs. For example, the ACE polymorphism may show age-specific influence on one health trait, and also antagonistically influence several other health traits (e.g., Hamelin et al. 2011; Helbecque et al. 2009; Higaki et al. 2000; Konoshita et al. 2001; Lehmann et al. 2005).

Another study found that the cumulative mortality from infections during 10 years of follow-up of oldestold individuals with higher total cholesterol levels was less than half that of those with normal or lower concentrations (Weverling-Rijnsburger et al. 1997). An increased risk of dying from respiratory disease and infection is major life threat in the senescent state due to deteriorated stress responses and slower recovery (Padgett et al. 1998). An elevated cholesterol may help the body to cope better with such challenges of aging (Ravnskov 2003). 
Altogether, the available evidence suggests that an age-dependency of genetic influence on health traits and survival is frequently encountered. Some genes may change their effect on person's vulnerability to death with age from "bad" to neutral to "good", towards extreme ages. Established non-genetic "risk factors", such as high cholesterol and elevated blood pressure, may also become beneficial at oldest old ages, in relation to all-cause mortality. This may seem counterintuitive, but could potentially be explained by opposite effects of genes and their products on development of some disease and senescence related phenotypes. Changes in internal $\mathrm{G} \times \mathrm{E}$ (e.g., due to aging and ontogeny related metabolic transitions in the body) may also contribute to the age-specific effects of genes. Environmental exposures, genetic background, lifestyle, medications and other factors may modulate the age-specific influence of genetic variants on health related phenotypes and on survival. This makes development of efficient personalized medicine a challenging problem (Schork 2015).

\section{Epistasis and mortality selection}

Genetic interactions may influence susceptibility to death and generate a mortality selection process that can change the genetic structure of heterogeneous population cohorts with age. This process may help keep "risk alleles" in the genomes of long-lived people. As discussed above, the population frequency of some "risk alleles/genotypes" may change U-shape-like with age: decrease from middle to old age, and then increase towards extreme ages (Bergman et al. 2007; De Benedictis et al. 1998; Yashin et al. 1999). There may be several reasons for this behavior. Some of them were discussed above, such as change in effect of gene on a person's vulnerability during aging (from "bad" in middle life to "good" at advanced ages) due to ontogeny and senescence related changes in internal $\mathrm{G} \times \mathrm{E}$, or due to the opposite influence of gene on some disease and senescence related phenotypes. Another mechanism may involve epistasis.

The term epistasis broadly refers to gene-gene interaction, such as when an allele of one gene modifies the phenotypic effect of another allele at another locus (e.g., (Cordell 2002). Most relevant to the topic of this paper are epistatic interactions that can change the effect of an allele on phenotype from deleterious to beneficial upon the presence of another allele in another locus. There are several types of epistatic effects and not all of them may result in increasing the fraction of "risk alleles" among the oldest old. Also, not all of them may involve "prolongevity" alleles as modifying gene variants. To better illustrate this, we outline several situations in which epistasis may differentially impact the agedynamics of allelic frequencies:

(i) Assume that a certain "risk allele" in one gene interacts with another allele in another locus, and this interaction neutralizes the deleterious effect of the risk allele on disease risk or survival. Since only some carriers of the risk allele will also have the "neutralizing" allele in their genomes, while other will not, the proportion of individuals who do not carry the neutralizing allele will decline with age. The proportion of carriers of both alleles, however, is not expected to increase if epistasis just eliminates the deleterious property of the risk allele. The proportion of the carriers of the risk allele will decline tending to approach a constant level with increasing age.

(ii) In case the neutralizing allele also favors longevity and keeps this property in combination with the risk allele of the other gene, the proportion of the risk allele will tend to increase with advancing age. This may contribute to situations in which potentially deleterious alleles are found among longlived individuals in similar or sometimes even higher proportions as in younger controls (Bladbjerg et al. 1999; Beekman et al. 2010; Freudenberg-Hua et al. 2014).

(iii) The epistatic interaction between the risk allele and the modifying allele in another locus may change the impact of the risk allele on vulnerability from deleterious to beneficial. In this case the proportion of individuals carrying the risk allele may increase with age so that the frequency of the original risk allele may be higher among the oldest-old compared to the middle-aged individuals. Note that in this scenario the modifying allele may not necessarily belong to the group of "longevity" alleles, although this could 
happen. Other individuals who carry the risk allele in one locus and do not carry the advantageous modifying allele in the other locus will tend to die out earlier and be wiped out of the cohort.

(iv) In addition to the type of epistasis in which a "good" allele in one locus may alleviate the effect of a "bad" allele in another gene or even make such an allele protective, there may also exist a positive antagonistic epistasis, in which two deleterious alleles (each separately having a detrimental effect on phenotype) may become less deleterious, neutral, or even beneficial when acting together. This type of epistasis may also contribute to a presence of "risk" alleles in genomes of long-lived people.

Research on the role of epistasis in determining human longevity has been rather limited in the past; however evidence of a significant impact of genetic interactions on health and survival is quickly growing in both human and animal studies (Tan et al. 2002; Gregersen et al. 2006; He et al. 2010; Moore 2003; Yamamoto et al. 2009; Trindade et al. 2009; Snitkin and Segre 2011; Niemi et al. 2005; Napolioni et al. 2011a, b; Jazwinski et al. 2010; Tan et al. 2013). Below are several examples of studies suggesting that "risk" variants may become less damaging, neutral or even beneficial in aged humans, as result of gene-gene interaction.

Genetic interactions that significantly contribute to human longevity have been found between SNPs in FOXO1A and FOXO3A genes (Tan et al. 2013). Zeng et al. (2010) reported that the positive effect of FOXO3A and negative effect of FOXO1A on longevity may largely compensate each other if one carries both, though the positive impact of FOXO3A was overall stronger.

It was suggested that individuals with exceptional longevity may carry "risk" alleles for common diseases because the detrimental effects of such alleles may be "buffered" by beneficial pro-longevity alleles in other genes (Bergman et al. 2007). The authors provided examples of the "buffering" pro-longevity genotypes (CETP VV, APOC3 CC), as well as the "buffered" ones (potentially deleterious alleles of KLOTHO and LPA genes). In a more recent paper, the U-shaped frequency curve for the MTP CC genotype (i.e., a lower frequency at ages 55-85, and a higher frequency in those who lived 90+) was explained in terms that the MTP CC is a deleterious genotype which is "buffered" by any of the three "longevity" genotypes of CETP, APOC3, or ADIPOQ (Huffman et al. 2012). In these examples, a pro-longevity variant could "buffer" the negative effect of the risk allele as result of epistasis.

A case of a positive antagonistic epistasis was explored by Mansoori et al. (2012) who found a significant association of the $\mathrm{C}$ allele of rs1801131 polymorphism in the MTHFR gene with AD. They also found a significant association of the $\mathrm{C}$ allele of another SNP rs1800795 in IL-6 gene with vascular dementia $(\mathrm{VaD})$, where the CC genotype increased the odds of $\mathrm{VaD}$ by 2.2-fold. However, the presence of the CC genotype of rs1801131 (in the MTHFR gene) nullified the detrimental effect of the CC genotype of rs1800795 (in IL-6 gene) in carriers of the two genotypes (Mansoori et al. 2012). Another study found that deleterious effects of single variants in the ADRB2 and ACE genes on the risk of MI can be altered by interactions between the two genes (Kulminski et al. 2010).

With a rapidly increasing number of relevant studies, the role of epistasis in determining human longevity should soon be supported with a larger pool of direct evidence. Also, an important issue for personalized prevention and developing pro-longevity interventions is to better understand how the epistatic effects on human health and lifespan are modulated by age, gender, and internal and external exposures, including medications.

\section{Gene-environment interaction and other factors}

The $\mathrm{G} \times \mathrm{E}$ determines the "norm of reaction"- the range of phenotypic manifestation of a genotype across the possible range of environments. Some genotypes may significantly vary in their phenotypic manifestation between different environments, and the same genetic variant may sometimes behave as "risk allele" in one environment and as neutral or protective factor in another. Figure 3 illustrates this with a hypothetical example of the change in $\mathrm{G} \times \mathrm{E}$ over time. In this figure, the effect of genotype on phenotype (e.g., disease risk) is different in different period-specific environments, and it may change over 


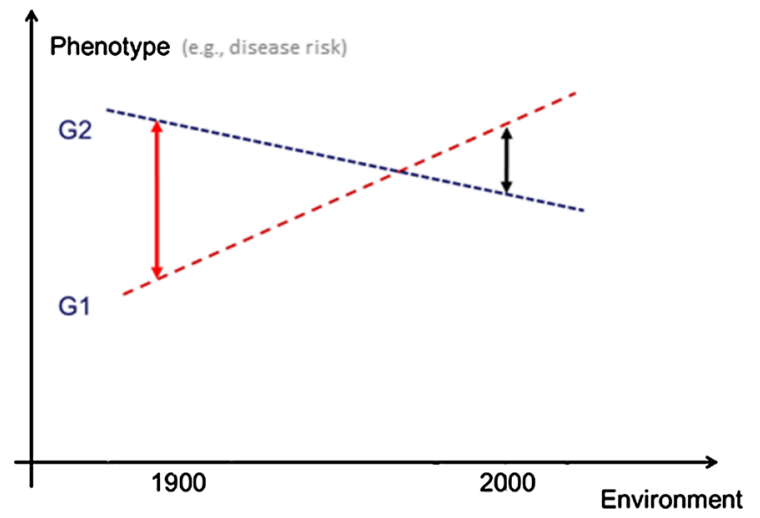

Fig. 3 A hypothetical example of the change in $G \times E$ interaction over time. The $\mathrm{G} \times \mathrm{E}$ determines the "norm of reaction"- the range of possible phenotypic manifestations of a genotype across different environments. It can contribute to situations in which the genotype behaves as a risk factor for a disease in one environment, but as neutral or protective factor in another environment

time from beneficial (lowering the risk) to detrimental (increasing the risk), and vice versa. Similarly, the effect of genotype on phenotype may change over place (due to population-specific environments), gender (due to differences in both $\mathrm{GxG}$ and $\mathrm{G} \times \mathrm{E}$ interactions between males and females) and age (due to changes in both internal and external environments occurring during aging). The $\mathrm{G} \times \mathrm{E}$ interaction is an important factor contributing to a highly conditional character of genetic influence on longevity and to a lack of replication in genetic association studies. Indeed, if a genetic variant increases risk of some major disease in certain environment today, this environment may be different from that experienced by the long-lived people in the past, so that this variant may not necessary pose the same risk to its long-lived carriers over the course of their lives.

Probably most "extreme" examples illustrating the high importance of the $\mathrm{G} \times \mathrm{E}$ in determining lifespan come from Mendelian disorders. For example, phenylketonuria (PKU) is a well-known autosomal recessive genetic disorder characterized by a mutation in the PAH gene encoding the enzyme phenylalanine hydroxylase. The PKU can lead to severe intellectual disability and other serious medical problems when affected children are allowed to eat common food. However, when treated with a strict phenylalaninerestricted diet, PKU patients can have a normal lifespan with normal mental development (van
Spronsen 2010). That is, the effect of this Mendelian mutation can be nullified by a $\mathrm{G} \times \mathrm{E}$ due to dietary change. This reminds that even genetic mutations with high penetrance and potentially dramatic impact on health may significantly vary in their expressivity and therefore in the effect on lifespan upon presence or absence of certain environmental factors.

In previous sections we mentioned the role of internal $\mathrm{G} \times \mathrm{E}$ in age-specific influence of genes on vulnerability to death, among other factors. Here we emphasize the role of the $\mathrm{G} \times \mathrm{E}$ in population-, exposure-, sex-, and generation- specific effects of genes. Such effects can be of mixed origin, and involve both genetic and non-genetic causes, such as differences in study design, statistical approaches and population structure, but they can also be due to $\mathrm{G} \times \mathrm{E}$. Since $\mathrm{G} \times \mathrm{E}$ is a broadly observed phenomenon in genetic association studies, with thousands of relevant publications, here we will provide only few representative examples suggesting that $\mathrm{G} \times \mathrm{E}$ can be major contributor to a highly conditional character of genetic influence on health and lifespan.

Interactions between genes and life style exposures such as smoking and diet may significantly modify the health effects of genetic polymorphisms that have been implicated in longevity. It was shown, for example, that the impact of the APOE e4 allele on dementia can be modified by exposure to tobacco smoking in a rather non-expected way. Smokers were at relatively decreased risk of cognitive deterioration in e4 carriers, but the risk was increased in noncarriers (Dufouil et al. 2000). In a large sample of a Mediterranean population followed up over a 10-year period, saturated fat intake substantially modified the effect of the APOE polymorphism on CHD risk. When saturated fat provided less than $10 \%$ of energy, no significant association between the APOE polymorphism and CHD risk was observed. However, with higher intake, the differences between e2 and e4 carriers became significant and pronounced (Corella et al. 2011). This result stresses a major role of diet in neutralizing the deleterious effects of the "risk" allele on health phenotypes. More recently, a study involving co-authors of this paper showed that the effect of FOXO genotypes on cognitive disability in the Chinese oldest old is strongly modified by regular tea drinking at around age 60 (Zeng et al. 2015). 
In addition, the mitochondrial superoxide dismutase 2 (SOD2) gene polymorphism rs4880 (47T $>C$, Val16Ala) provides a good example of a highly context dependent effect of genetic variation on health and survival. It has been shown to influence multiple health disorders, with frequent trade-offs and outcomes that can be substantially modified by both $\mathrm{G} \times \mathrm{G}$ and $\mathrm{G} \times \mathrm{E}$. For example, no associations of colorectal, breast and prostate cancer risks and survival with the rs4880 polymorphism were found in several large studies (Blein et al. 2014; Chen et al. 2014a). However, $\mathrm{G} \times \mathrm{E}$ appears to modify the effect of this polymorphism on cancer. The CC (Ala/Ala) genotype may negatively affect survival of breast cancer patients who received cyclophosphamide chemotherapy (Glynn et al. 2009). The higher iron and low vegetable intake in TT (Val/Val) carriers was associated with increased risk of aggressive prostate cancer (Choi et al. 2008). In Greek-Cypriot women, high fish and vegetable intake reduced breast cancer risk in TT genotypes (Kakkoura et al. 2015). As for other diseases, the TT genotype was associated with CHD in females but not males (Jones et al. 2010), and with CHD in hereditary hemochromatosis patients (Valenti et al. 2004), thus suggesting a GxG impact. As for the $\mathrm{C}$ allele, a meta-analysis and smaller studies concluded that it has protective effects on risks of diabetes and its complications (Nakanishi et al. 2008; Tian et al. 2011). However, there is also substantial evidence of the negative impact of the $\mathrm{C}$ allele on survival of people in critical condition. The $\mathrm{C}$ allele was associated with significantly higher frequency of septic shock among critically ill patients (Paludo et al. 2013). This frequency was highest for patients with both the SOD2 47C and glutathione peroxidase 593T allele as compared with other genotype combinations, thus suggesting additional impact of $\mathrm{GxG}$ on the rs4880 manifestation (Majolo et al. 2015). The multiple conditional and trade-off-like effects of rs4880 polymorphism on different health traits could be a reason that no consistent influence of this polymorphism on human longevity was found. Specifically, only moderately decreased mortality in individuals with the $\mathrm{C}$ allele $(\mathrm{HR}=0.91$ ) was reported in a Danish cohort (Soerensen et al. 2009); however no association was detected between the $\mathrm{C}$ (or $\mathrm{T}$ ) variant and longevity in a long-lived sample of the German population (Gentschew et al. 2013).

Gender-specific effects of genes on disease risks are also very common. For example, an earlier research in the Framingham Study Offspring cohort reported an association of the APOE e4 with the age-adjusted prevalence of heart disease, which had a more pronounced effect in women (Wilson et al. 1994). A more recent study in the same cohort confirmed that the APOE e4 is a risk factor for CVD primarily in women, and also found that it can be protective against cancer primarily in men (Kulminski et al. 2013). A genetic variation in an anti-inflammatory IL-10 cytokine was shown to be associated with longevity only in male but not in female centenarians (Lio et al. 2002). Such gender effects could be due to both $\mathrm{GxG}$ and $\mathrm{G} \times \mathrm{E}$ differences between men and women. A genetic variant that negatively influences survival only in men could still be prevalent among the long-lived people because the majority of centenarians are women.

Broadly observed population-specific effects of genes also suggest the role of $\mathrm{G} \times \mathrm{E}$ in modifying the influence of genetic "risk factors" on health traits. In studies of Italian centenarians and other long-living people from different European regions, the association of polymorphism in IL-6 with longevity was markedly population-specific (Pes et al. 2004) (Di Bona et al. 2009). As mentioned above, elevated $\mathrm{Lp}$ (a) blood levels have been linked to a higher risk of CVD in many studies. Respectively, the LPA gene polymorphisms that increase the $\mathrm{Lp}$ (a) levels were thought to increase CVD risk as well. However, this was not the case for at least some populations (Enkhmaa et al. 2011; Qi et al. 2012). This indicates that the LPA variants may be genetic "risk factors" for CVD only in certain environments. These results may also indicate that the association between Lp(a) level and CVD could be because of confounding, or inverse causation. Estimates of direct associations of the LPA variants with disease risk are needed to evaluate the causality of the genetic influence. The 4G4G genotype of PAI-1 (Plasminogen activator inhibitor-1), may serve as another example of the population/study specific influence of genotype on health outcomes that can vary from deleterious to neutral to beneficial in relation to the same health trait across different populations. While the $4 \mathrm{G} 4 \mathrm{G}$ genotype was found to be protective against stroke in some populations, it was also found to have no effect or even increase the risk of stroke in other populations (Hoekstra et al. 2003; van Goor et al. 2005; Wiklund et al. 2005). Understanding factors and mechanisms responsible for the differences 
in impact of the 4G4G genotype on stroke occurrence in different populations may provide useful insights into efficient personalized preventive strategies for carriers of and non-carriers of this genotype.

Generation-specific effects of genes may create a situation in which a genetic variant that increases risk of some disease in parents may become neutral or beneficial in relation to the same disease (or survival) in offspring. One of few studies on intergenerational trade-offs between health and survival traits found that the offspring of mothers with $\mathrm{AD}$ have increased longevity compared to the offspring of mothers without AD (Silverman et al. 2008). Period-specific $\mathrm{G} \times \mathrm{E}$ could contribute to these effects.

In sum, an important message from the studies discussed in this section is that the influence of genotype on health traits and longevity is often conditional and cannot be described in simple terms such as "harmful" or "beneficial". The allele showing a deleterious effect in one environment will not necessarily demonstrate this same property in other environment. The $\mathrm{G} \times \mathrm{E}$ could contribute to a typically poor replication of results of genetic association studies. "Longevity genes" that might help someone to become a centenarian in the past may not necessarily help to achieve extreme longevity nowadays. Long-lived people from different populations were exposed to distinct environments in their lives, so they may have different sets of genes associated with their longevity.

\section{Concluding remarks}

Genetic "risks factors" for major diseases are often found in genomes of long-lived people and do not seem to compromise longevity. The review of current evidence performed in this paper suggests that the trade-off-like and conditional effects of genes on phenotypes of health and aging could play central role in this phenomenon and in determining longevity. Such effects are common and may result in situations in which the same genetic variant can be both a disease risk factor and a pro-longevity variant.

The effect of a particular gene on a person's vulnerability to death at a given age is an aggregated outcome of increased and decreased risks of/mortalities from various conditions that are influenced by that gene in the presence of other genetic factors and the person's history of internal and external exposures. When a gene variant increases risk of certain disease, this fact itself does not guarantee that the same variant will negatively affect total survival chances of an individual because it may, in principle, be protective against some other major health disorder or senescence related phenotype. The effect of a genetic "risk factor" on a person's survival and longevity may thus be negative, neutral or positive, depending on the interplay of its detrimental and beneficial effects on multiple health and aging traits, and it can be modulated by age, internal and external environments, genetic surrounding, and other factors. If the protective effect prevails, then the frequency of such a variant may be higher in the long-lived people.

Investigating the trade-off like and conditional effects of genes is critically important both for understanding the relationships between aging, health decline and longevity and for facilitating progress in personalized prevention and treatment. Such effects have to be taken into account to develop efficient methods of personalized medicine (Schork 2015). For instance, the existence of a trade-off between cancer and $\mathrm{AD}$ implies that some factors that promote development of AD may potentially be protective against cancer, and that measures aiming to prevent AD may increase cancer risk in some individuals. This and similar possibilities should be considered by health policy makers, who develop both personalized and population-wide preventive strategies. In addition to reducing the risks of separate diseases, an important focus of prevention could be a reduction of all-cause mortality risk in individuals.

The highly conditional character of genetic influence on longevity is likely to also contribute to the weakness of genetic signals, and the lack of replication in genetic association studies. Different sets of genes may be activated in response to different age- and population-specific environments and exposures, so that the same health or survival outcome will not necessarily be associated with the same set of genes in the different populations or age groups.

The relationships discussed in this paper have an additional important implication for further studies of the roles of genetic factors in human health and lifespan. In particular, they indicate that an increase in sample size of study subjects, traditionally recommended in cases of the low significance, small effect sizes, and a lack of replication in GWAS, may not 
always be a good strategy (e.g., Kulminski et al. 2015). Indeed, the sample size can be increased by pooling the data from several studies of independent populations. However, some genetic variants may have opposite effects on the trait of interest, e.g., due to differences in histories of environmental exposures, or due to the differences in genetic backgrounds of individuals comprising the populations. Hence, such pooling may not necessarily improve estimates of the genetic association.

Overall, the results of this review suggest that there is probably no such thing as unconditionally 'bad' or 'good' allele of a common genetic polymorphism in regard to its role in human aging, health and lifespan. Our analyses indicate that integration and coordination of studies of (i) pleiotropic, including trade-offlike, influence of genes on phenotypes of health and senescence, (ii) age-patterns of the genetic effects on individual vulnerability to death, (iii) gene-gene, and (iv) $\mathrm{G} \times$ Es effects on lifespan, among other factors, may substantially improve our understanding of the dynamic relationships among genetic and non-genetic regulators of aging, health and longevity in humans.

Acknowledgments The research reported in this publication was in part supported by the National Institute on Aging of the National Institutes of Health grants R01AG046860, P01AG043352. The content is solely the responsibility of the authors and does not necessarily represent the official views of the National Institutes of Health.

\section{References}

Agarwal R (2009) Blood pressure components and the risk for end-stage renal disease and death in chronic kidney disease. Clin J Am Soc Nephrol 4:830-837. doi:10.2215/cjn. 06201208

Akushevich I, Kravchenko J, Ukraintseva S, Arbeev K, Yashin AI (2012) Age patterns of incidence of geriatric disease in the U.S. elderly population: medicare-based analysis. J Am Geriatr Soc 60:323-327. doi:10.1111/j.1532-5415.2011. 03786.x

Akushevich I, Kravchenko J, Ukraintseva S, Arbeev K, Kulminski A, Yashin AI (2013) Morbidity risks among older adults with pre-existing age-related diseases. Exp Gerontol 48:1395-1401. doi:10.1016/j.exger.2013.09.005

Alvarez R et al (1999) Angiotensin converting enzyme and endothelial nitric oxide synthase DNA polymorphisms and late onset Alzheimer's disease. J Neurol Neurosurg Psychiatry 67:733-736. doi:10.1136/jnnp.67.6.733

Bader G, Zuliani G, Kostner GM, Fellin R (1998) Apolipoprotein $\mathrm{E}$ polymorphism is not associated with longevity or disability in a sample of Italian octo- and nonagenarians. Gerontology 44:293-299

Baggio G et al (1998) Lipoprotein(a) and lipoprotein profile in healthy centenarians: a reappraisal of vascular risk factors. Faseb J 12:433-437

Bartke A (2012) Healthy aging: is smaller better?-a mini-review. Gerontology 58:337-343. doi:10.1159/000335166

Beekman M et al (2010) Genome-wide association study (GWAS)-identified disease risk alleles do not compromise human longevity. Proc Natl Acad Sci USA 107:18046-18049. doi:10.1073/pnas.1003540107

Benes P et al (2001) The C766T low-density lipoprotein receptor related protein polymorphism and coronary artery disease, plasma lipoproteins, and longevity in the Czech population. J Mol Med 79:116-120. doi:10.1007/s001090100196

Bergman A, Atzmon G, Ye K, MacCarthy T, Barzilai N (2007) Buffering mechanisms in aging: a systems approach toward uncovering the genetic component of aging. PLoS Comput Biol 3:e170. doi:10.1371/journal.pcbi.0030170

Bhattacharyya $\mathrm{T}$ et al (2008) Relationship of paraoxonase 1 (PON1) gene polymorphisms and functional activity with systemic oxidative stress and cardiovascular risk. JAMA 299:1265-1276. doi:10.1001/jama.299.11.1265

Bladbjerg EM, Andersen-Ranberg K, de Maat MPM, Kristensen SR, Jeune B, Gram J, Jespersen J (1999) Longevity is independent of common variations in genes associated with cardiovascular risk. Thromb Haemost 82:1100-1105

Blein S, Berndt S, Joshi AD, Campa D, Ziegler RG, Riboli E, Cox DG (2014) Factors associated with oxidative stress and cancer risk in the Breast and Prostate Cancer Cohort Consortium. Free Radic Res 48:380-386. doi:10.3109/ 10715762.2013 .875168

Bonafe $\mathrm{M}$ et al (1999) p53 variants predisposing to cancer are present in healthy centenarians. Am J Hum Genet 64:292-295. doi:10.1086/302196

Bonafe M et al (2002) Genetic analysis of Paraoxonase (PON1) locus reveals an increased frequency of Arg192 allele in centenarians. Eur J Hum Genet 10:292-296. doi:10.1038/ sj.ejhg.5200806

Brattstrom L et al (1998) A common methylenetetrahydrofolate reductase gene mutation and longevity. Atherosclerosis 141:315-319. doi:10.1016/s0021-9150(98)00154-3

Brozzetti A et al (2010) Cytotoxic T lymphocyte antigen-4 Ala17 polymorphism is a genetic marker of autoimmune adrenal insufficiency: Italian association study and metaanalysis of European studies. Eur $\mathrm{J}$ Endocrinol 162:361-369. doi:10.1530/eje-09-0618

Cambien F et al (1992) Deletion polymorphism in the gene for angiotensin-converting enzyme is a potent risk factor for myocardial-infarction. Nature 359:641-644. doi:10.1038/ $359641 \mathrm{a} 0$

Chen J et al (1996) A methylenetetrahydrofolate reductase polymorphism and the risk of colorectal cancer. Cancer Res 56:4862-4864

Chen Y, Dong S, He M, Qi T, Zhu W (2013) Angiotensinconverting enzyme insertion/deletion polymorphism and risk of myocardial infarction in an updated meta-analysis based on 34993 participants. Gene 522:196-205. doi:10. 1016/j.gene.2013.03.076

Chen $\mathrm{C}$ et al (2014a) Association between six genetic polymorphisms and colorectal cancer: a meta-analysis. Genet 
Test Mol Biomark 18:187-195. doi:10.1089/gtmb.2013. 0425

Chen NY et al (2014b) Enrichment of MTHFR $677 \mathrm{~T}$ in a Chinese long-lived cohort and its association with lipid modulation. Lipids Health Dis 13:104. doi:10.1186/1476$511 \mathrm{x}-13-104$

Choi JY et al (2008) Iron intake, oxidative stress-related genes (MnSOD and MPO) and prostate cancer risk in CARET cohort. Carcinogenesis 29:964-970. doi:10.1093/carcin/ bgn056

Cirulli E, Zhu M, Shianna KV, Ge D, Goldstein DB (2011) Next generation sequencing of centenarian and control genomes. Paper presented at the International Congress of Human Genetics, Montreal

Clarke R et al (2009) Genetic variants associated with Lp(a) lipoprotein level and coronary disease. N Engl J Med 361:2518-2528. doi:10.1056/NEJMoa0902604

Coffey CS, Asselbergs FW, Hebert PR, Hillege HL, Li Q, Moore JH, van Gilst WH (2011) The association of the metabolic syndrome with PAI-1 and t-PA levels. Cardiol Res Pract 2011:541467

Conti E, Musumeci MB, De Giusti M, Dito E, Mastromarino V, Autore C, Volpe M (2011) IGF-1 and atherothrombosis: relevance to pathophysiology and therapy. Clin Sci 120:377-402. doi: $10.1042 / \operatorname{cs} 20100400$

Cordell HJ (2002) Epistasis: what it means, what it doesn't mean, and statistical methods to detect it in humans. Hum Mol Genet 11:2463-2468. doi:10.1093/hmg/11.20.2463

Corella D et al (2011) Saturated fat intake and alcohol consumption modulate the association between the APOE polymorphism and risk of future coronary heart disease: a nested case-control study in the Spanish EPIC cohort. J Nutr Biochem 22:487-494. doi:10.1016/j.jnutbio.2010. 04.003

Correa PA, Gomez LM, Cadena J, Anaya JM (2005) Autoimmunity and tuberculosis. Opposite association with TNF polymorphism. J Rheumatol 32:219-224

Dahlen GH (1994) Lp(a) lipoprotein in cardiovascular disease. Atherosclerosis 108:111-126

De Benedictis G, Franceschi C (1998) The genetics of successful aging. Aging-Clin Exp Res 10:147-148

De Benedictis G, Franceschi C (2006) The unusual genetics of human longevity Science of aging knowledge environment. Sci Aging Knowl Environ. doi:10.1126/sageke. 2006.10.pe20

De Benedictis G et al (1998) Age-related changes of the $3^{\prime}$ APOB-VNTR genotype pool in ageing cohorts. Ann Hum Genet 62:115-122. doi:10.1017/s0003480098006757

De Benedictis G et al (2001) Recent advances in human genelongevity association studies. Mech Ageing Dev 122:909-920. doi:10.1016/s0047-6374(01)00247-0

Di Bona D et al (2009) Effect of interleukin-6 polymorphisms on human longevity: a systematic review and meta-analysis. Ageing Res Rev 8:36-42. doi:10.1016/j.arr.2008.09. 001

Driver JA et al (2012) Inverse association between cancer and Alzheimer's disease: results from the Framingham Heart Study. Br Med J 344:e1442. doi:10.1136/bmj.e1442

Duffy DL et al (2010) IRF4 variants have age-specific effects on nevus count and predispose to melanoma. Am J Hum Genet 87:6-16. doi:10.1016/j.ajhg.2010.05.017
Dufouil C, Tzourio C, Brayne C, Berr C, Amouyel P, Alperovitch A (2000) Influence of apolipoprotein E genotype on the risk of cognitive deterioration in moderate drinkers and smokers. Epidemiology 11:280-284. doi:10.1097/ 00001648-200005000-00009

Enkhmaa B, Anuurad E, Zhang W, Tran T, Berglund L (2011) Lipoprotein(a): genotype-phenotype relationship and impact on atherogenic risk. Metab Syndr Relat Disord 9:411-418. doi:10.1089/met.2011.0026

Erqou S et al (2009) Lipoprotein(a) concentration and the risk of coronary heart disease, stroke, and nonvascular mortality. JAMA 302:412-423. doi:10.1001/jama.2009.1063

Faure-Delanef L, Baudin B, Beneteau-Burnat B, Beaudoin JC, Giboudeau J, Cohen D (1998) Plasma concentration, kinetic constants, and gene polymorphism of angiotensin I-converting enzyme in centenarians. Clin Chem 44:2083-2087

Finch CE, Morgan TE (2007) Systemic inflammation, infection, ApoE alleles, and Alzheimer disease: a position paper. Curr Alzheimer Res 4:185-189

Freudenberg-Hua Y et al (2014) Disease variants in genomes of 44 centenarians. Mol Genet Genom Med 2:438-450. doi:10.1002/mgg3.86

Galinsky D et al (1997) Analysis of the apo E apo C-I, angiotensin converting enzyme and methylenetetrahydrofolate reductase genes as candidates affecting human longevity. Atherosclerosis 129:177-183. doi:10.1016/s00219150(96)06027-3

Garasto S, Berardelli M, DeRango F, Mari V, Feraco E, De Benedictis G (2004) A study of the average effect of the 3'APOB-VNTR polymorphism on lipidemic parameters could explain why the short alleles $(<35$ repeats) are rare in centenarians. BMC Med Genet 5:3. doi:10.1186/14712350-5-3

Garatachea N, Marin PJ, Lucia A (2013) The ACE DD genotype and D-allele are associated with exceptional longevity: a meta-analysis. Ageing Res Rev 12:1079-1087. doi:10. 1016/j.arr.2013.04.001

Gentschew L, Flachsbart F, Kleindorp R, Badarinarayan N, Schreiber S, Nebel A (2013) Polymorphisms in the superoxidase dismutase genes reveal no association with human longevity in Germans: a case-control association study. Biogerontology 14:719-727. doi:10.1007/s10522013-9470-3

Ghaderi A (2011) CTLA4 gene variants in autoimmunity and cancer: a comparative review. Iran J Immunol 8:127-149

Glynn SA et al (2009) A mitochondrial target sequence polymorphism in manganese superoxide dismutase predicts inferior survival in breast cancer patients treated with cyclophosphamide. Clin Cancer Res 15:4165-4173. doi:10.1158/1078-0432.ccr-09-0119

Gong LL et al (2012) Association of tissue plasminogen activator and plasminogen activator inhibitor polymorphism with myocardial infarction: a meta-analysis. Thromb Res 130:e43-51. doi:10.1016/j.thromres.2012.06.015

Gregersen JW et al (2006) Functional epistasis on a common MHC haplotype associated with multiple sclerosis. Nature 443:574-577. doi:10.1038/nature05133

Hamelin BA, Zakrzewski-Jakubiak M, Robitaille NM, Bogaty P, Labbe L, Turgeon J (2011) Increased risk of myocardial infarction associated with angiotensin-converting enzyme 
gene polymorphism is age dependent. J Clin Pharmacol 51:1286-1292. doi:10.1177/0091270010382420

Hanahan D, Weinberg RA (2011) Hallmarks of cancer: the next generation. Cell 144:646-674. doi:10.1016/j.cell.2011.02. 013

Hartz A, He T, Ross JJ (2012) Risk factors for colon cancer in 150,912 postmenopausal women. Cancer Causes Control 23:1599-1605. doi:10.1007/s10552-012-0037-4

He X, Qian W, Wang Z, Li Y, Zhang J (2010) Prevalent positive epistasis in Escherichia coli and Saccharomyces cerevisiae metabolic networks. Nat Genet 42:272-276. doi:10.1038/ ng.524

Heijmans BT, Westendorp RG, Knook DL, Kluft C, Slagboom PE (1999) Angiotensin I-converting enzyme and plasminogen activator inhibitor-1 gene variants: risk of mortality and fatal cardiovascular disease in an elderly population-based cohort. J Am Coll Cardiol 34:1176-1183

Helbecque N, Codron V, Cottel D, Amouyel P (2009) An age effect on the association of common variants of ACE with Alzheimer's disease. Neurosci Lett 461:181-184. doi:10. 1016/j.neulet.2009.06.006

Hendrie HC et al (2014) APOE epsilon4 and the risk for Alzheimer disease and cognitive decline in African Americans and Yoruba. Int Psychogeriatr/IPA 26:977-985. doi:10. $1017 / \mathrm{s} 1041610214000167$

Higaki J et al (2000) Deletion allele of angiotensin-converting enzyme gene increases risk of essential hypertension in Japanese men: the Suita Study. Circulation 101:2060-2065

Hoekstra T, Geleijnse JM, Kluft C, Giltay EJ, Kok FJ, Schouten EG (2003) 4G/4G genotype of PAI-1 gene is associated with reduced risk of stroke in elderly. Stroke 34:2822-2828. doi:10.1161/01.str.0000098004.26252.eb

Holstege $\mathrm{H}$ et al (2011) A longevity reference genome generated from the world's oldest woman. Paper presented at the International Congress of Human Genetics, Montreal

Hsieh Wu J (2011) Lipoprotein(a) in vascular disease, cancer and longevity. Chang Gung Med J 34:555-564

Hsu CY, McCulloch CE, Darbinian J, Go AS, Iribarren C (2005) Elevated blood pressure and risk of end-stage renal disease in subjects without baseline kidney disease. Arch Intern Med 165:923-928. doi:10.1001/archinte.165.8.923

$\mathrm{Hu} \mathrm{L}$ et al (2010) CTLA-4 gene polymorphism +49 A/G contributes to genetic susceptibility to two infection-related cancers-hepatocellular carcinoma and cervical cancer. Hum Immunol 71:888-891. doi:10.1016/j.humimm.2010. 05.023

Hua Y, Zhao H, Kong Y, Ye M (2011) Association between the MTHFR gene and Alzheimer's disease: a meta-analysis. Int J Neurosci 121:462-471. doi:10.3109/00207454.2011. 578778

Huang Y, Han S, Li Y, Mao Y, Xie Y (2007) Different roles of MTHFR C677T and A1298C polymorphisms in colorectal adenoma and colorectal cancer: a meta-analysis. J Hum Genet 52:73-85. doi:10.1007/s10038-006-0082-5

Hubner RA, Houlston RS (2007) MTHFR C677T and colorectal cancer risk: a meta-analysis of 25 populations. Int J Cancer 120:1027-1035. doi:10.1002/ijc.22440

Huffman DM, Deelen J, Ye K, Bergman A, Slagboom EP, Barzilai N, Atzmon G (2012) Distinguishing between longevity and buffered-deleterious genotypes for exceptional human longevity: the case of the MTP gene.
J Gerontol Seri A 67:1153-1160. doi:10.1093/gerona/ gls 103

Husemoen LL et al (2014) MTHFR C677T genotype and cardiovascular risk in a general population without mandatory folic acid fortification. Eur J Nutr 53:1549-1559. doi:10. 1007/s00394-014-0659-2

Iacopetta B, Heyworth J, Girschik J, Grieu F, Clayforth C, Fritschi L (2009) The MTHFR C677T and DeltaDNMT3B $\mathrm{C}-149 \mathrm{~T}$ polymorphisms confer different risks for right- and left-sided colorectal cancer. Int J Cancer 125:84-90. doi:10.1002/ijc. 24324

Iribarren JL et al (2008) Postoperative bleeding in cardiac surgery - the role of tranexamic acid in patients homozygous for the $5 \mathrm{G}$ polymorphism of the plasminogen activator inbibitor-1 gene. Anesthesiology 108:596-602

Iwaki T et al (2011) Life-threatening hemorrhage and prolonged wound healing are remarkable phenotypes manifested by complete plasminogen activator inhibitor-1 deficiency in humans. J Thromb Haemost 9:1200-1206. doi:10.1111/j. 1538-7836.2011.04288.x

Jazwinski SM et al (2010) HRAS1 and LASS1 with APOE are associated with human longevity and healthy aging. Aging Cell 9:698-708. doi:10.1111/j.1474-9726.2010.00600.x

Jones DA, Prior SL, Tang TS, Bain SC, Hurel SJ, Humphries SE, Stephens JW (2010) Association between the rs4880 superoxide dismutase $2(\mathrm{C}>\mathrm{T})$ gene variant and coronary heart disease in diabetes mellitus. Diabetes Res Clin Pract 90:196-201. doi:10.1016/j.diabres.2010.07.009

Kakkoura MG et al (2015) MnSOD and CAT polymorphisms modulate the effect of the Mediterranean diet on breast cancer risk among Greek-Cypriot women. Eur J Nutr. doi:10.1007/s00394-015-0971-5

Kirkwood TB, Rose MR (1991) Evolution of senescence: late survival sacrificed for reproduction. Philos Trans R Soc Lond Ser B 332:15-24. doi:10.1098/rstb.1991.0028

Konoshita T et al (2001) Effect of ACE gene polymorphism on age at renal death in polycystic kidney disease in Japan. Am J Kidney Dis 37:113-118

Kulminski A, Ukraintseva SV, Arbeev KG, Manton KG, Oshima J, Martin GM, Yashin AI (2008) Association between APOE epsilon 2/epsilon 3/epsilon 4 polymorphism and disability severity in a national long-term care survey sample. Age Ageing 37:288-293. doi:10.1093/ageing/ afn003

Kulminski AM, Culminskaya IV, Ukraintseva SV, Arbeev KG, Akushevich I, Land KC, Yashin AI (2010) Polymorphisms in the ACE and ADRB2 genes and risks of aging-associated phenotypes: the case of myocardial infarction. Rejuvenation Res 13:13-21. doi:10.1089/rej.2009.0905

Kulminski AM et al (2011) Trade-off in the effects of the apolipoprotein E polymorphism on the ages at onset of CVD and cancer influences human lifespan. Aging Cell 10:533-541. doi:10.1111/j.1474-9726.2011.00689.x

Kulminski AM, Culminskaya I, Arbeev KG, Ukraintseva SV, Arbeeva L, Yashin AI (2013) Trade-off in the effect of the APOE gene on the ages at onset of cardiovascular disease and cancer across ages, gender, and human generations. Rejuvenation Res 16:28-34. doi:10.1089/rej.2012.1362

Kulminski AM, Arbeev KG, Culminskaya I, Ukraintseva SV, Stallard E, Province MA, Yashin AI (2015) Trade-offs in the effects of the apolipoprotein E polymorphism on risks 
of diseases of the heart, cancer, and neurodegenerative disorders: insights on mechanisms from the Long Life Family Study. Rejuvenation Res 18:128-135. doi:10.1089/ rej.2014.1616

Leander K, Wiman B, Hallqvist J, Sten-Linder M, de Faire U (2003) PAI-1 level and the PAI-1 4G/5G polymorphism in relation to risk of non-fatal myocardial infarction. Thromb Haemost 89:1064-1071

Lee JH, Cheon YH, Woo RS, Song DY, Moon C, Baik TK (2012) Evidence of early involvement of apoptosis inducing factor-induced neuronal death in Alzheimer brain. Anat Cell Biol 45:26-37. doi:10.5115/acb.2012.45.1.26

Lehmann DJ et al (2005) Large meta-analysis establishes the ACE insertion-deletion polymorphism as a marker of Alzheimer's disease. Am J Epidemiol 162:305-317. doi:10.1093/aje/kwi202

Lescai F, Marchegiani F, Franceschi C (2009) PON1 is a longevity gene: results of a meta-analysis. Ageing Res Rev 8:277-284. doi:10.1016/j.arr.2009.04.001

Levine AJ et al (2010) Genetic variability in the MTHFR gene and colorectal cancer risk using the colorectal cancer family registry. Cancer Epidemiol Biomark Prev 19:89-100. doi:10.1158/1055-9965.epi-09-0727

Lewington S et al (2008) Blood cholesterol and vascular mortality by age, sex, and blood pressure: a meta-analysis of individual data from 61 prospective studies with 55000 vascular deaths (vol 370, pg 1829, 2007). Lancet 372:292

Lio D et al (2002) Gender-specific association between -1082 IL-10 promoter polymorphism and longevity. Genes Immun 3:30-33. doi:10.1038/sj.gene.6363827

Lloyd-Jones DM et al (2002) Lifetime risk for developing congestive heart failure: the Framingham Heart Study. Circulation 106:3068-3072

Ma J et al (1997) Methylenetetrahydrofolate reductase polymorphism, dietary interactions, and risk of colorectal cancer. Cancer Res 57:1098-1102

Majolo F, Oliveira Paludo FJ, Ponzoni A, Graebin P, Dias FS, Alho CS (2015) Effect of 593C $>$ T GPx1 SNP alone and in synergy with $47 \mathrm{C}>\mathrm{T}$ SOD2 SNP on the outcome of critically ill patients. Cytokine 71:312-317. doi:10.1016/j. cyto.2014.10.020

Mannucci PM et al (1997) Gene polymorphisms predicting high plasma levels of coagulation and fibrinolysis proteins-a study in centenarians. Arterioscler Thromb Vasc Biol 17:755-759

Mansoori N et al (2012) MTHFR (677 and 1298) and IL-6-174 G/C genes in pathogenesis of Alzheimer's and vascular dementia and their epistatic interaction. Neurobiol Aging. doi:10.1016/j.neurobiolaging.2011.09.018

Mari D, Coppola R, Provenzano R (2008) Hemostasis factors and aging. Exp Gerontol 43:66-73. doi:10.1016/j.exger. 2007.06.014

Mooijaart SP et al (2011) Polymorphisms associated with type 2 diabetes in familial longevity: The Leiden Longevity Study. Aging 3:55-62

Moore JH (2003) The ubiquitous nature of epistasis in determining susceptibility to common human diseases. Hum Hered 56:73-82.

Musaro A (2012) To the heart of the problem. mIGF-1: local effort for global impact. Aging 4:377-378
Nakanishi S et al (2008) Manganese superoxide dismutase Ala16Val polymorphism is associated with the development of type 2 diabetes in Japanese-Americans. Diabetes Res Clin Pract 81:381-385. doi:10.1016/j.diabres.2008.06.003

Napolioni V et al (2011a) Age- and gender-specific epistasis between ADA and TNF-alpha influences human life-expectancy. Cytokine 56:481-488. doi:10.1016/j.cyto.2011. 07.023

Napolioni V, Gianni P, Carpi FM, Predazzi IM, Lucarini N (2011b) APOE haplotypes are associated with human longevity in a Central Italy population: evidence for epistasis with HP $1 / 2$ polymorphism. Clin Chim Acta 412:1821-1824. doi:10.1016/j.cca.2011.06.012

Nebel A et al (2011) A genome-wide association study confirms APOE as the major gene influencing survival in long-lived individuals. Mech Ageing Dev 132:324-330. doi:10.1016/ j.mad.2011.06.008

Neuman MD, Silber JH, Magaziner JS, Passarella MA, Mehta S, Werner RM (2014) Survival and functional outcomes after hip fracture among nursing home residents. JAMA Intern Med 174:1273-1280. doi:10.1001/jamainternmed.2014. 2362

Niemi AK et al (2005) A combination of three common inherited mitochondrial DNA polymorphisms promotes longevity in Finnish and Japanese subjects. Eur J Hum Genet 13:166-170. doi:10.1038/sj.ejhg.5201308

Nikolopoulos GK et al (2014) The association between plasminogen activator inhibitor type 1 (PAI-1) levels, PAI-1 4G/5G polymorphism, and myocardial infarction: a Mendelian randomization meta-analysis. Clin Chem Lab Med 52:937-950. doi:10.1515/cclm-2013-1124

Padgett DA, MacCallum RC, Sheridan JF (1998) Stress exacerbates age-related decrements in the immune response to an experimental influenza viral infection. J Gerontol Ser A 53:B347-B353

Paludo FJ et al (2013) Higher frequency of septic shock in septic patients with the 47C allele (rs4880) of the SOD2 gene. Gene 517:106-111. doi:10.1016/j.gene.2012.10.078

Park JW et al (2009) Candidate gene polymorphisms for diabetes mellitus, cardiovascular disease and cancer are associated with longevity in Koreans. Exp Mol Med 41:772-781. doi:10.3858/emm.2009.41.11.083

Park J-H, Wacholder S, Gail MH, Peters U, Jacobs KB, Chanock SJ, Chatterjee N (2010) Estimation of effect size distribution from genome-wide association studies and implications for future discoveries. Nat Genet 42:570-575

Peng Q, Lao X, Huang X, Qin X, Li S, Zeng Z (2015) The MTHFR C677T polymorphism contributes to increased risk of Alzheimer's disease: evidence based on 40 casecontrol studies. Neurosci Lett 586:36-42. doi:10.1016/j. neulet.2014.11.049

Pepe G, Di Perna V, Resta F, Lovecchio M, Chimienti G, Colacicco AM, Capurso A (1998) In search of a biological pattern for human longevity: impact of apo A-IV genetic polymorphisms on lipoproteins and the hyper-Lp(a) in centenarians. Atherosclerosis 137:407-417. doi:10.1016/ s0021-9150(97)00290-6

Pes GM et al (2004) Association between longevity and cytokine gene polymorphisms. A study in Sardinian centenarians. Aging Clin Exp Res 16:244-248 
Petersen LK, Christensen K, Kragstrup J (2010) Lipid-lowering treatment to the end? A review of observational studies and RCTs on cholesterol and mortality in $80+$-year olds. Age Ageing 39:674-680. doi:10.1093/ageing/afq129

Qi Q, Workalemahu T, Zhang C, Hu FB, Qi L (2012) Genetic variants, plasma lipoprotein(a) levels, and risk of cardiovascular morbidity and mortality among two prospective cohorts of type 2 diabetes. Eur Heart J 33:325-334. doi:10. 1093/eurheartj/ehr350

Ravnskov U (2003) High cholesterol may protect against infections and atherosclerosis Qjm-an. Int $\mathbf{J}$ Med 96:927-934. doi:10.1093/qjmed/hcg150

Renehan AG, Zwahlen M, Minder C, O'Dwyer ST, Shalet SM, Egger M (2004) Insulin-like growth factor (IGF)-I, IGF binding protein-3, and cancer risk: systematic review and meta-regression analysis. Lancet 363:1346-1353. doi:10. 1016/s0140-6736(04)16044-3

Rigat B, Hubert C, Alhenc-Gelas F, Cambien F, Corvol P, Soubrier F (1990) An insertion/deletion polymorphism in the angiotensin I-converting enzyme gene accounting for half the variance of serum enzyme levels. J Clin Investig 86:1343-1346. doi:10.1172/jci114844

Robinson EB, McGrath LM, Santangelo SL (2013) Life course approaches to the genetic epidemiology of mental illness. In: Koenen KC, Rudenstine S, Susser E, Galea S (eds) A life course approach to mental disorders, pp 194-203. McGraw-Hill, New York. doi:10.1093/acprof:oso/ 9780199657018.003.0018

Roe CM et al (2010) Cancer linked to Alzheimer disease but not vascular dementia. Neurology 74:106-112. doi:10.1212/ WNL.0b013e3181c91873

Ruiz JR, Moran M, Arenas J, Lucia A (2011) Strenuous endurance exercise improves life expectancy: it's in our genes. Br J Sports Med 45:159-161. doi:10.1136/bjsm. 2010.075085

Ruiz LA, Zalacain R, Capelastegui A, Bilbao A, Gomez A, Uranga A, Espana PP (2014) Bacteremic pneumococcal pneumonia in elderly and very elderly patients: host- and pathogen-related factors, process of care, and outcome. J Gerontol Seri A 69:1018-1024. doi:10.1093/gerona/ glt 288

Sawabe M et al (2012) Low Lipoprotein(a) concentration is associated with cancer and all-cause deaths: a populationbased cohort study (The JMS Cohort Study). Plos One. doi:10.1371/journal.pone.0031954

Schachter F, Fauredelanef L, Guenot F, Rouger H, Froguel P, Lesueurginot L, Cohen D (1994) Genetic associations with human longevity at the apoe and ace loci. Nat Genet 6:29-32. doi: $10.1038 / \mathrm{ng} 0194-29$

Schork NJ (2015) Personalized medicine: time for one-person trials. Nature 520:609-611. doi:10.1038/520609a

Sebastiani P et al (2011) Whole genome sequences of a male and female supercentenarian, ages greater than 114 years. Front Genet 2:90

Shi $\mathrm{H}$ et al (2012) Genetic variants influencing human aging from late-onset Alzheimer's disease (LOAD) genome-wide association studies (GWAS). Neurobiol Aging 33:1849.e18451818. doi:10.1016/j.neurobiolaging.2012.02.014

Silverman JM et al (2008) Increased longevity in offspring of mothers with Alzheimer's disease. Am J Med Genet Part B 147B:754-758. doi:10.1002/ajmg.b.30676
Slattery ML, Potter JD, Samowitz W, Schaffer D, Leppert M (1999) Methylenetetrahydrofolate reductase, diet, and risk of colon cancer. Cancer Epidemiol Biomark Prev 8:513-518

Snitkin ES, Segre D (2011) Epistatic interaction maps relative to multiple metabolic phenotypes. PLoS Genet 7:e1001294. doi:10.1371/journal.pgen.1001294

Soerensen M, Christensen K, Stevnsner T, Christiansen L (2009) The Mn-superoxide dismutase single nucleotide polymorphism rs4880 and the glutathione peroxidase 1 single nucleotide polymorphism rs 1050450 are associated with aging and longevity in the oldest old. Mech Ageing Dev 130:308-314. doi:10.1016/j.mad.2009.01.005

Solfrizzi V et al (2009) All-cause mortality and competing risks of fatal and nonfatal vascular events in the italian longitudinal study on aging: impact of Lipoprotein(a). Rejuvenation Res 12:395-402. doi:10.1089/rej.2009.0865

Sonntag WE, Csiszar A, deCabo R, Ferrucci L, Ungvari Z (2012) Diverse roles of growth hormone and insulin-like growth factor-1 in mammalian aging: progress and controversies. J Gerontol Ser A 67:587-598. doi:10.1093/ gerona/gls115

Tabares-Seisdedos R et al (2011) No paradox, no progress: inverse cancer comorbidity in people with other complex diseases. Lancet Oncol 12:604-608. doi:10.1016/s14702045(11)70041-9

Tabares-Seisdedos R, Rubenstein JL (2013) Inverse cancer comorbidity: a serendipitous opportunity to gain insight into CNS disorders. Nat Rev Neurosci 14:293-304. doi:10. 1038/nrn3464

Tan Q, De Benedictis G, Ukraintseva SV, Franceschi C, Vaupel JW, Yashin AI (2002) A centenarian-only approach for assessing gene-gene interaction in human longevity. Eur J Hum Genet 10:119-124. doi:10.1038/sj.ejhg.5200770

Tan Q, Soerensen M, Kruse TA, Christensen K, Christiansen L (2013) A novel permutation test for case-only analysis identifies epistatic effects on human longevity in the FOXO gene family. Aging Cell 12:690-694. doi:10.1111/acel. 12092

Taylor HS, Manson JE (2011) Update in hormone therapy use in menopause. J Clin Endocrinol Metab 96:255-264. doi:10. 1210/jc.2010-0536

Tian C, Fang S, Du X, Jia C (2011) Association of the C47T polymorphism in SOD2 with diabetes mellitus and diabetic microvascular complications: a meta-analysis. Diabetologia 54:803-811. doi:10.1007/s00125-010-2004-5

Trindade S, Sousa A, Xavier KB, Dionisio F, Ferreira MG, Gordo I (2009) Positive epistasis drives the acquisition of multidrug resistance. PLOS Genet. doi:10.1371/journal. pgen. 1000578

Ukraintseva S (2005) "Bad" in the young_- "good" in the old: is this consistent with the antagonistic pleiotropy concept? (Comment on Dr. G.M. Martin's "How is the evolutionary biological theory of aging holding up against mounting attacks?") Am Aging Assoc Newsl 4-5

Ukraintseva SV, Yashin AI (2001) How individual age-associated changes may influence human morbidity and mortality patterns. Mech Ageing Dev 122:1447-1460

Ukraintseva SV, Yashin AI (2003a) Individual aging and cancer risk: how are they related? Demogr Res 9-8:163-196

Ukraintseva SV, Yashin AI (2003b) Opposite phenotypes of cancer and aging arise from alternative regulation of 
common signaling pathways. Ann N Y Acad Sci 1010:489-492

Ukraintseva SV, Arbeev KG, Yashin AI (2008) Epidemiology of hormone-associated cancers as a reflection of age. Adv Exp Med Biol 630:57-71

Ukraintseva SV et al (2010) Trade-offs between cancer and other diseases: do they exist and influence longevity? Rejuvenation Res 13:387-396. doi:10.1089/rej.2009.0941

Ulmer H, Kelleher C, Diem G, Concin H (2004) Why Eve is not Adam: prospective follow-up in 149650 women and men of cholesterol and other risk factors related to cardiovascular and all-cause mortality. J Women's Health (2002) 13:41-53. doi:10.1089/154099904322836447

Ulrich CM et al (1999) Colorectal adenomas and the C677T MTHFR polymorphism: evidence for gene-environment interaction? Cancer Epidemiol Biomark Prev 8:659-668

Ungvari Z, Csiszar A (2012) The emerging role of IGF-1 deficiency in cardiovascular aging: recent advances. J Gerontol Ser A 67:599-610. doi:10.1093/gerona/gls072

Vairaktaris E et al (2006) Plasminogen activator inhibitor-1 polymorphism is associated with increased risk for oral cancer. Oral Oncol 42:888-892. doi:10.1016/j. oraloncology.2005.12.005

Valenti L et al (2004) The mitochondrial superoxide dismutase A16V polymorphism in the cardiomyopathy associated with hereditary haemochromatosis. J Med Genet 41:946-950. doi:10.1136/jmg.2004.019588

van Aken $\mathrm{MO}$ et al (2002) No increase in mortality and morbidity among carriers of the $\mathrm{C} 282 \mathrm{Y}$ mutation of the hereditary haemochromatosis gene in the oldest old: the Leiden 85-plus Study. Eur J Clin Invest 32:750-754. doi:10.1046/j.1365-2362.2002.01062.x

van Bemmel T, Woittiez K, Blauw GJ, van der Sman-de Beer F, Dekker FW, Westendorp RGJ, Gussekloo J (2006) Prospective study of the effect of blood pressure on renal function in old age: The Leiden 85-plus study. J Am Soc Nephrol 17:2561-2566. doi:10.1681/asn.2005090902

van Goor ML, Garcia EG, Leebeek F, Brouwers GJ, Koudstaal P, Dippel D (2005) The plasminogen activator inhibitor (PAI-I) 4G/5G promoter polymorphism and PAI-I levels in ischemic stroke-a case-control study. Thromb Haemost 93:92-96. doi:10.1160/th04-09-0560

van Heemst D et al (2005) Variation in the human TP53 gene affects old age survival and cancer mortality. Exp Gerontol 40:11-15

van Spronsen FJ (2010) Phenylketonuria: a 21st century perspective. Nat Rev Endocrinol 6:509-514. doi:10.1038/ nrendo.2010.125

van Vliet P, Oleksik AM, van Heemst D, de Craen AJM, Westendorp RGJ (2010) Dynamics of traditional metabolic risk factors associate with specific causes of death in old age. J Gerontol Ser A 65:488-494. doi:10.1093/gerona/ glq014

Vasan RS et al (2003) Serum insulin-like growth factor I and risk for heart failure in elderly individuals without a previous myocardial infarction: The Framingham Heart Study. Ann Intern Med 139:642-648

Vinciguerra M, Musaro A, Rosenthal N (2010) Regulation of muscle atrophy in aging and disease. Protein metabolism and homeostasis in aging. Adv Exp Med Biol 694:211-233
Vylliotis A et al (2013) Effect of thrombosis-related gene polymorphisms upon oral cancer: a regression analysis. Anticancer Res 33:4033-4039

Wang B et al (2006) The insertion polymorphism in angiotensinconverting enzyme gene associated with the APOE epsilon 4 allele increases the risk of late-onset Alzheimer disease. J Mol Neurosci 30:267-271. doi:10.1385/jmn:30:3:267

Wang L, Jiang Z, Qiu H, Tang W, Duan T, Wang L (2015) Associations between CTLA-4 +49 A/G (rs231775) polymorphism and cancer risk: a meta-analysis based on 52 case-control studies. Int J Clin Exp Med 8:6835-6851

Werner H, Bruchim I (2012) IGF-1 and BRCA1 signalling pathways in familial cancer. Lancet Oncol 13:e537-544. doi:10.1016/s1470-2045(12)70362-5

Weverling-Rijnsburger AW, Blauw GJ, Lagaay AM, Knook DL, Meinders AE, Westendorp RG (1997) Total cholesterol and risk of mortality in the oldest old. Lancet 350:1119-1123

Wiklund PG et al (2005) Plasminogen activator inhibitor-1 4G/5G polymorphism and risk of stroke-replicated findings in two nested case-control studies based on independent cohorts. Stroke 36:1661-1665. doi:10.1161/01.str.0000174485. 10277.24

Wilson PW, Myers RH, Larson MG, Ordovas JM, Wolf PA, Schaefer EJ (1994) Apolipoprotein E alleles, dyslipidemia, and coronary heart disease. The Framingham Offspring Study. Jama 272:1666-1671

Yamamoto A, Anholt RR, MacKay TF (2009) Epistatic interactions attenuate mutations affecting startle behaviour in Drosophila melanogaster. Genet Res 91:373-382. doi:10. 1017/s0016672309990279

Yang Q et al (2012) Prospective study of methylenetetrahydrofolate reductase (MTHFR) variant C677T and risk of all-cause and cardiovascular disease mortality among 6000 US adults. Am J Clin Nutr 95:1245-1253. doi:10.3945/ ajcn.111.022384

Yashin AI et al (1999) Genes, demography, and life span: the contribution of demographic data in genetic studies on aging and longevity. Am J Hum Genet 65:1178-1193

Yashin AI et al (2001) Have the oldest old adults ever been frail in the past? A hypothesis that explains modern trends in survival. J Gerontol Seri A 56:B432-442

Yashin AI, Ukraintseva SV, Akushevich IV, Arbeev KG, Kulminski A, Akushevich L (2009) Trade-off between cancer and aging: what role do other diseases play? Evidence from experimental and human population studies. Mech Ageing Dev 130:98-104. doi:10.1016/j.mad.2008.03.006

Yashin AI et al (2015) Genetics of aging, health, and survival: dynamic regulation of human longevity related traits. Front Genet 6:122. doi:10.3389/fgene.2015.00122

Zajc Petranovic M et al (2012) Angiotensin-converting enzyme deletion allele is beneficial for the longevity of Europeans. Age 34:583-595. doi:10.1007/s11357-011-9270-0

Zeng Y et al (2010) Effects of FOXO genotypes on longevity: a biodemographic analysis. J Gerontol Ser A 65:1285-1299. doi:10.1093/gerona/glq156

Zeng Y et al (2015) $\mathrm{G} \times \mathrm{E}$ interactions between FOXO genotypes and tea drinking are significantly associated with cognitive disability at advanced ages in China. J Gerontol Ser A 70:426-433. doi:10.1093/gerona/glu060 